\title{
Modelling homogeneous regions of social vulnerability to malaria in Rwanda
}

\author{
Jean Pierre Bizimana, ${ }^{1,2}$ Stefan Kienberger, ${ }^{3}$ Michael Hagenlocher, ${ }^{3}$ \\ Emmanuel Twarabamenye ${ }^{1,2}$ \\ ${ }^{1}$ Geography Department, College of Science and Technology, University of Rwanda, Kigali; \\ ${ }^{2}$ Centre for Geographic Information Systems and Remote Sensing, Huye, Rwanda; \\ ${ }^{3}$ Department of Geoinformatics - Z_GIS, University of Salzburg, Salzburg, Austria
}

\begin{abstract}
Despite the decline in malaria incidence due to intense interventions, potentials for malaria transmission persist in Rwanda. To eradicate malaria in Rwanda, strategies need to expand beyond approaches that focus solely on malaria epidemiology and also consider the socioeconomic, demographic and biological/disease-related factors that determine the vulnerability of potentially exposed populations. This paper analyses current levels of social vulnerability to malaria in
\end{abstract}

Correspondence: Jean Pierre Bizimana, Geography Department, College of Science and Technology, University of Rwanda, Avenue de l'Armee, 3900 Kigali, Rwanda.

Tel: +250.788493379 .

E-mail: jpbizimana@nur.ac.rw

Key words: Malaria; Social vulnerability; Regionalisation; Integrated geons; Rwanda.

Acknowledgements: the research leading to these results received funding from the European Union's Seventh Framework Programme (FP7/20072013) under grant agreement no. 266327 HEALTHY FUTURES Project (http://www.healthyfutures.eu/). We also thank the DHS Program of the U.S. Agency for International Development (USAID) for providing the socioeconomic data for Rwanda. We are grateful to Raphael Spiekermann and Helena Rebecca Merschdorf for proofreading the draft of the manuscript.

Contributions: JPB, SK and MH made substantial contributions to the study conception and design, data collection, as well as the interpretation of the results and drafting the manuscript. JPB and MH were involved in data processing, analysis, and visualisation. ET, SK and MH critically revised the manuscript for important intellectual content. All authors proofread and approved the final manuscript.

Received for publication: 31 July 2015.

Revision received: 4 February 2016.

Accepted for publication: 24 February 2016.

(C) Copyright J.P. Bizimana et al., 2016

Licensee PAGEPress, Italy

Geospatial Health 2016; 11(s1):404

doi:10.4081/gh.2016.404

This article is distributed under the terms of the Creative Commons Attribution Noncommercial License (CC BY-NC 4.0) which permits any noncommercial use, distribution, and reproduction in any medium, provided the original author(s) and source are credited.
Rwanda by integrating a set of weighted vulnerability indicators. The paper uses regionalisation techniques as a spatially explicit approach for delineating homogeneous regions of social vulnerability to malaria. This overcomes the limitations of administrative boundaries for modelling the trans-boundary social vulnerability to malaria. The utilised approach revealed high levels of social vulnerability to malaria in the highland areas of Rwanda, as well as in remote areas where populations are more susceptible. Susceptibility may be due to the populations' lacking the capacity to anticipate mosquito bites, or lacking resilience to cope with or recover from malaria infection. By highlighting the most influential indicators of social vulnerability to malaria, the applied approach indicates which vulnerability domains need to be addressed, and where appropriate interventions are most required. Interventions to improve the socioeconomic development in highly vulnerable areas could prove highly effective, and provide sustainable outcomes against malaria in Rwanda. This would ultimately increase the resilience of the population and their capacity to better anticipate, cope with, and recover from possible infection.

\section{Introduction}

Despite various interventions to reduce the burden of malaria, the disease persists in many countries of the developing world. In 2012 there were approximately 562,000 malaria deaths in Africa, despite a slow decline since 2004 (WHO, 2014). Malaria decrease in Sub-Saharan Africa was generally associated with intense interventions and reduced vector density due to changing rainfall patterns (Meyrowitsch et al., 2011). Although considerable progress has been made in many countries, the general malaria burden remains high, particularly in young children and pregnant women (Roll Back Malaria, 2005). The Plasmodium (P.) falciparum prevalence rates in Rwanda increased until the late 1990 s and early 2000 s, after which a marked decrease was noted (Stern et al., 2011). Since 2004, interventions to prevent and control malaria in Rwanda have resulted in a substantial decline in malaria transmission, particularly as a result of improved access to effective treatment, increased use of bed nets, and indoor residual spraying (Karema et al., 2012). However, malaria incidence increased again between 2011 and 2012, revealing the fragility of the gains achieved (WHO, 2013). The results of an entomological survey of more than 50\% exophile entomological inoculation rate (EIR) around Kigali City is also an indicator of potential transmission gaps not addressed by existing interventions in Rwanda (Hakizimana et al., 2010). The EIR is a measure of exposure to infectious mosquitoes, usually interpreted as the number of $P$. falciparum infective bites received by an individual during 
a season or annually (Kilama et al., 2014).

Because no single approach to malaria elimination can be successful across the country, strategies that account for both socioeconomic and environmental settings in each region must be implemented in an integrated approach (Kienberger and Hagenlocher, 2014; Mboera et al., 2014; Hagenlocher and Castro, 2015). An integrated vector management (IVM) programme was recently adopted in Rwanda as a comprehensive framework for malaria interventions, based on local ecology, disease epidemiology and socioeconomic factors (USAID, 2014). The strategy encompasses environmental modifications through both infrastructural development and sanitation services, to regulate not only the vectors but also the exposure to mosquito bites. It also seeks to improve public health and quality of life, and to minimise social-disparities (Lizzi et al., 2014). In line with this integrative strategy for malaria elimination, identifying regions of high levels of social vulnerability to malaria can help decision-makers provide tailor-made interventions in the most vulnerable areas of Rwanda.

The current public health approach to malaria in Rwanda is still based on the Global Health Initiative strategy, which seeks to reduce malaria burden by funding specific interventions and strengthening the health care system (USAID, 2014). Although these programs have temporarily reduced the overall malaria infection, they are ineffective for sustaining malaria reductions without addressing the proximate causes of malaria transmission and ultimate causes of malaria. These causes are rooted in the social structure, agro-ecological settings, and demographic pressures observed in the country (Packard, 2007). If malaria reduction strategies concentrate solely on health care and malaria control other relevant factors that shape community health may be neglected, such as rural housing, food security, and employment (Morgan, 2001). Successful malaria elimination therefore needs to expand on classic approaches, which mostly focus on environmental factors, malaria parasites, and vectors, and should also consider the social, economic, demographic, and accessrelated (e.g. access to health care) factors that shape the vulnerability of the population (De Plaen et al., 2004; Kienberger and Hagenlocher, 2014; Hagenlocher and Castro, 2015).

Vulnerability assessments use a set of (weighted) indicators to simplify complex information in an aggregated measure, relevant for decisionmaking (Dickin et al., 2013). Most quantitative vulnerability assessments are based on administrative boundaries and thus tend to ignore the spatially explicit distribution of indicators (Brooks et al., 2005; Borderon, 2013; Hagenlocher et al., 2013; Kienberger et al., 2013b; Frazier et al., 2014; Bizimana et al., 2015). However, vector borne diseases (VBDs) like malaria do not respect such artificial boundaries, which are inappropriate for targeting specific and place-based interventions (Rytkönen, 2004). The assessment of social vulnerability to diseases based on administrative regions is not always an appropriate manner of spatially displaying vulnerability, since boundaries rarely correspond to the variations inherent in social vulnerability as a continuous phenomenon (King and Blackmore, 2013).To overcome the challenges outlined above, an integrated and spatially explicit approach for assessing social vulnerability to malaria infection is required. This has also been highlighted by Hongoh et al. (2011) and Kienberger and Hagenlocher (2014), who advocated for a spatially explicit and integrative assessment of vulnerability. In this regard a holistic risk and vulnerability framework, including a methodology for mapping social vulnerability to malaria, was developed by Kienberger and Hagenlocher (2014), and was recently applied to the entire East African Community (EAC) region. Hagenlocher and Castro (2015) also proposed a spatially explicit approach for mapping relative levels of malaria risk as a function of hazard (represented by malaria EIR), exposure, and vulnerability in Tanzania, where the final set of risk factors and their contribution to malaria endemicity was identified based on regression analysis. The results from the studies outlined above provide place-specific options for targeting malaria interventions among the most vulnerable populations. Nevertheless, such macro-level analyses, focusing on the East African regional scale or on larger countries such as Tanzania, may not perform well in representing malaria vulnerability and local capacities in each country, especially in Rwanda and Burundi, which are relatively small countries with high population densities. At the East Africa regional level, the difference in size between countries and subadministrative units does not allow a spatial comparison (Hagenlocher $e t$ al., 2014).

These studies have distinct implications for policy and decisionmaking as they facilitate prioritisation of interventions by indicating which factors need to be addressed in each area. In addressing key elements of (risk and) vulnerability to VBDs for a small country like Rwanda, which faces intensified pressure from environmental and socio-economic changes, a different understanding of the underlying drivers of social vulnerability to malaria infection may be required. Thus, there is a need to apply a high-resolution approach for modelling social vulnerability to malaria in Rwanda to bridge this gap. To model the regions of social vulnerability to malaria in Rwanda, this study is based on recently published works focusing on East Africa, such as Kienberger and Hagenlocher (2014) and Hagenlocher and Castro (2015). We applied a similar conceptual and methodological framework as the published works outlined above, but the advance of this paper relies on the spatial scale and better quality of data, which helped to reveal the hidden social vulnerability in Rwanda. The final social vulnerability index score is a combination of susceptibility to not withstanding malaria infection, and the lacking capacity to anticipate the exposure to mosquito bites, and to cope with or recover from infection.

\section{Materials and Methods}

\section{Study area}

Malaria stratification in Rwanda has been studied since the 1960 s by Meyus et al. (1962), who delineated malaria ecological zones based on altitude, climate, and malaria parasite prevalence. A malaria endemicity map for Rwanda, published by the Malaria Atlas Project, shows that malaria is highly endemic in the eastern lowlands, along the rivers near the bottom of the valleys in the central plateau, and in the southwestern Bugarama plain. The highlands exhibit a very low endemicity, or absence of malaria transmission (Gething et al., 2011). The map in Figure 1 shows the predicted spatial distribution of Plasmodium falciparum prevalence in children under five years old in Rwanda, and is based on the spatial interpolation of 2010 Demographic and Health Survey data in Rwanda (NISR, 2012c).

The above mentioned malaria eco-zones exhibit a micro-stratification, due to varying landscapes and farming activities. The existing malaria strata do not reflect the current situation anymore. A recent study highlighted significant modifications of climate in the highlands, noting a high rainfall decline and a strong temperature increase, which are anomalous for high altitudes (Henninger, 2013a). This changing climate may affect the geographic distribution of malaria, with a high impact on the most vulnerable populations (Martens et al., 1999).

\section{Conceptual framework}

The past decades have been marked by huge interest in the concept of vulnerability and associated conceptual frameworks (Cutter et al., 2000, 2003; Birkmann and Wisner, 2006; Birkmann et al., 2013; Kienberger and Hagenlocher, 2014; Hagenlocher and Castro, 2015). 
This study is based on a holistic risk and vulnerability framework, which is based on the MOVE Risk framework (Birkmann et al., 2013), and further developed by Kienberger and Hagenlocher (2014) in the context of VBDs. Figure 2 shows the adapted framework of social vulnerability to malaria, the main domains of vulnerability, as well as the final vulnerability indicators for each domain.

The adopted framework considers the key elements of social vulnerability, susceptibility, and lack of resilience (Kienberger and Hagenlocher, 2014; Hagenlocher and Castro, 2015). Susceptibility to malaria is determined by an individual's lacking ability to withstand malaria infection. The susceptibility can be classified as generic susceptibility or biological susceptibility. Generic susceptibility refers to factors leading to the predisposition of an individual to be affected by malaria. These factors include, for example, population pressure and density, livelihoods, agricultural practices, inaccessibility or poor access to transportation, as well as poverty. Biological susceptibility refers to the effectiveness with which an infective mosquito infects humans. This latter case is a function of immunity, which depends on age, pregnancy, or co-infection with other diseases (Bates et al., 2004). Women's immunity depreciates during pregnancy, while the immunity of young children is not yet fully developed (WHO, 2006). Besides, Human Immunodeficiency Virus (HIV) infection also increases malaria severity and incidences (Berg et al., 2014).

In the framework outlined herein, lack of resilience refers to the lacking capacity of societies and population groups to respond to and absorb negative impacts of malaria infection, as a result of the lacking capacity to anticipate, respond to and recover from a malaria episode (Hagenlocher et al., 2014). The resilience of a community is determined by its capacity to anticipate the exposure to mosquito bites, which may be influenced by education, knowledge about malaria transmission, prevention, protection measures, and housing conditions (Ricci, 2012). A resilient community is able to cope with malaria episodes using local opportunities to cope with or recover from malaria infection. This coping and recovery capacity relates to access to health care facilities, and to the ability to access effective, appropriate, and prompt medical treatment. Guided by the proposed framework, relevant indicators and required datasets for assessing social vulnerability to malaria infection were identified based on a review of literature.

\section{Justification of indicators}

A critical step in modelling homogenous regions of social vulnerability is the identification of a sound and valid set of indicators, and an appropriate dataset, which can be combined in a meaningful vulnerability index. Following the vulnerability framework published by Kienberger and Hagenlocher (2014), 19 relevant indicators that represent the multidimensional nature of social vulnerability to malaria have been selected from literature. Table 1 shows the vulnerability domains, indicators used, as well as the source of the corresponding datasets.

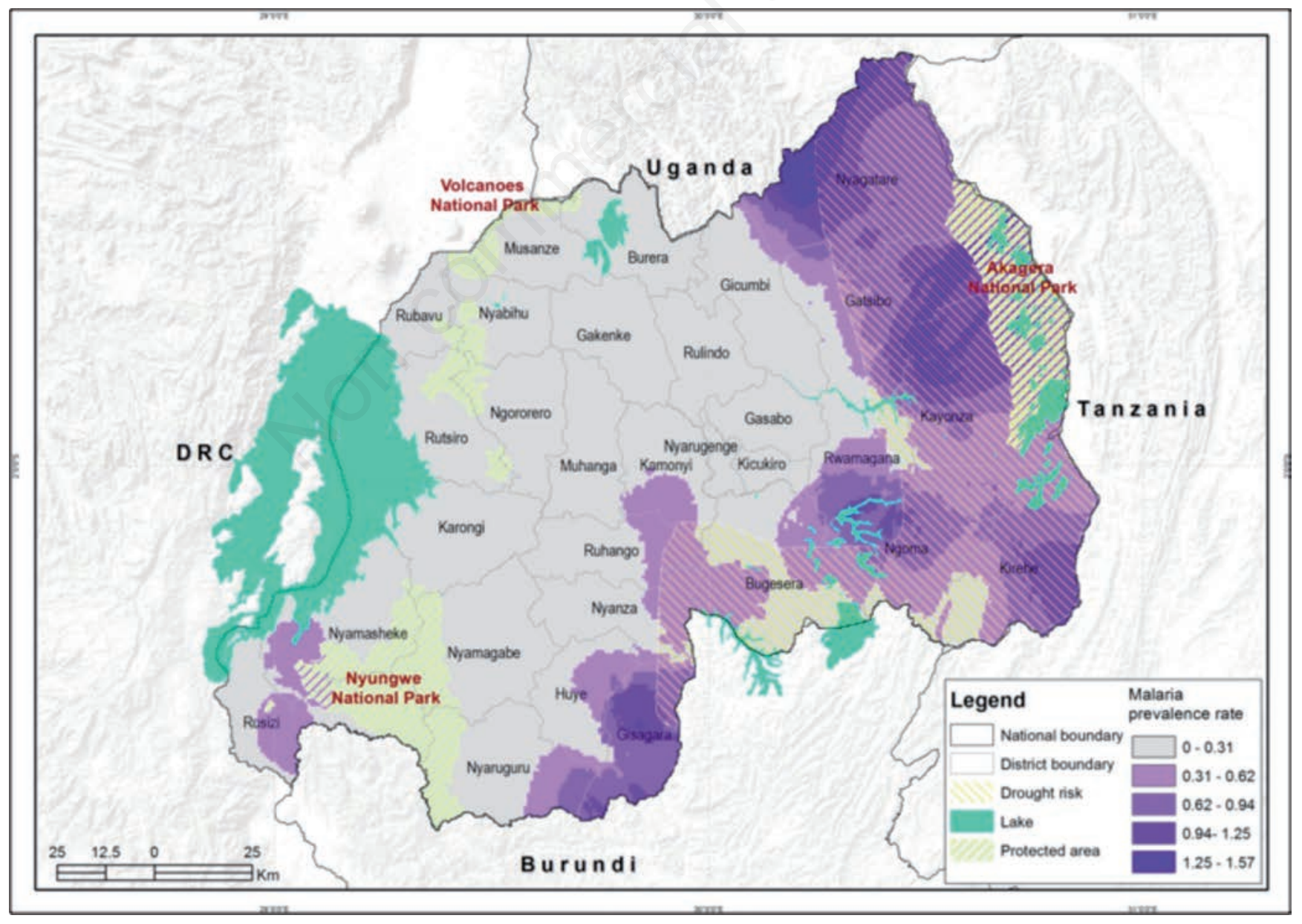

Figure 1. Plasmodium falciparum prevalence in Rwanda in 2010. 


\section{Generic susceptibility}

In rural areas, low population densities may not support malaria transmission (Snow et al., 1999a, 1999b). The Rwandan population increased considerably from 2.6 million in 1960 to 10.6 million in 2012, approximately (NISR, 2012b). Consequently, Rwanda has become the most densely populated country in Africa. This high population pressure has resulted in limited land resources and increased human exposure to malaria in the highlands (Lindsay and Martens, 1998). In addition, it has had a significant negative effect in environmental degradation and declining landholdings (Clay, 1992; Clay and Johnson, 1992); which have pushed people to settle near unsuitable sites with more exposure to mosquito bites (Thaxton, 2009). Malaria incidences are embedded in livelihood activities, which interplay with the ineffective use and non-use of bed nets (Dunn et al., 2011). Water-based livelihoods play an important role in malaria incidence, but they are not yet fully included in malaria control policies (Mboera et al., 2014). Agricultural practices that increase the outdoor mosquito biting exposure in Rwanda are: clothes not covering the farmer's body when they are involved in farming activities in irrigation schemes, overnight stays in farms to protect maize from unauthorised harvesters, and temporal shifting to rice farms. During the rice cultivation seasons, worker migrants move from highlands to stay overnight near the rice paddies where they are exposed to malaria vectors. Moreover, maize and rice intensification in the marshlands closer to homes, brick-making, fish- ponds, digging holes, and water storage for irrigation are the main water management activities that expose people to mosquito bites. Livelihoods largely focusing on extensive marshlands reclamation as a result of high population densities are likely to increase the exposure of populations to malaria in Rwanda (Nabahungu and Visser, 2013).

Access to a road network and transportation is a relevant development indicator covering generic access to a variety of services (Fedderke et al., 2006). Despite the relatively dense road network, offroad motorised transport is not viable in Rwanda due to steep slopes (Perschon-Heyen, 2001). Walking remains the predominant form of transportation in rural areas (UNECA, 2009). In mountainous areas, the rugged terrain and poor road infrastructure are the access barriers to malaria prevention and control interventions. During the rainy seasons, which often correspond to the peak of malaria transmission, patients may struggle to access health care due to poor roads. Decaying road infrastructure in remote areas may also prevent anti-malaria spraying interventions from reaching the isolated areas, leading to an increased risk of a malaria outbreak within the isolated communities (0'Meara et al., 2009). Besides, the transport cost exacerbates the vulnerability of the poor in rural areas, who have limited access to financial means, more than that of well-off families living in urban centers (Okwaraji et al., 2012). Physical accessibility to health facilities in relation to existing transportation means also influences where, when, and what type of health treatment is sought (Alegana et al., 2012).
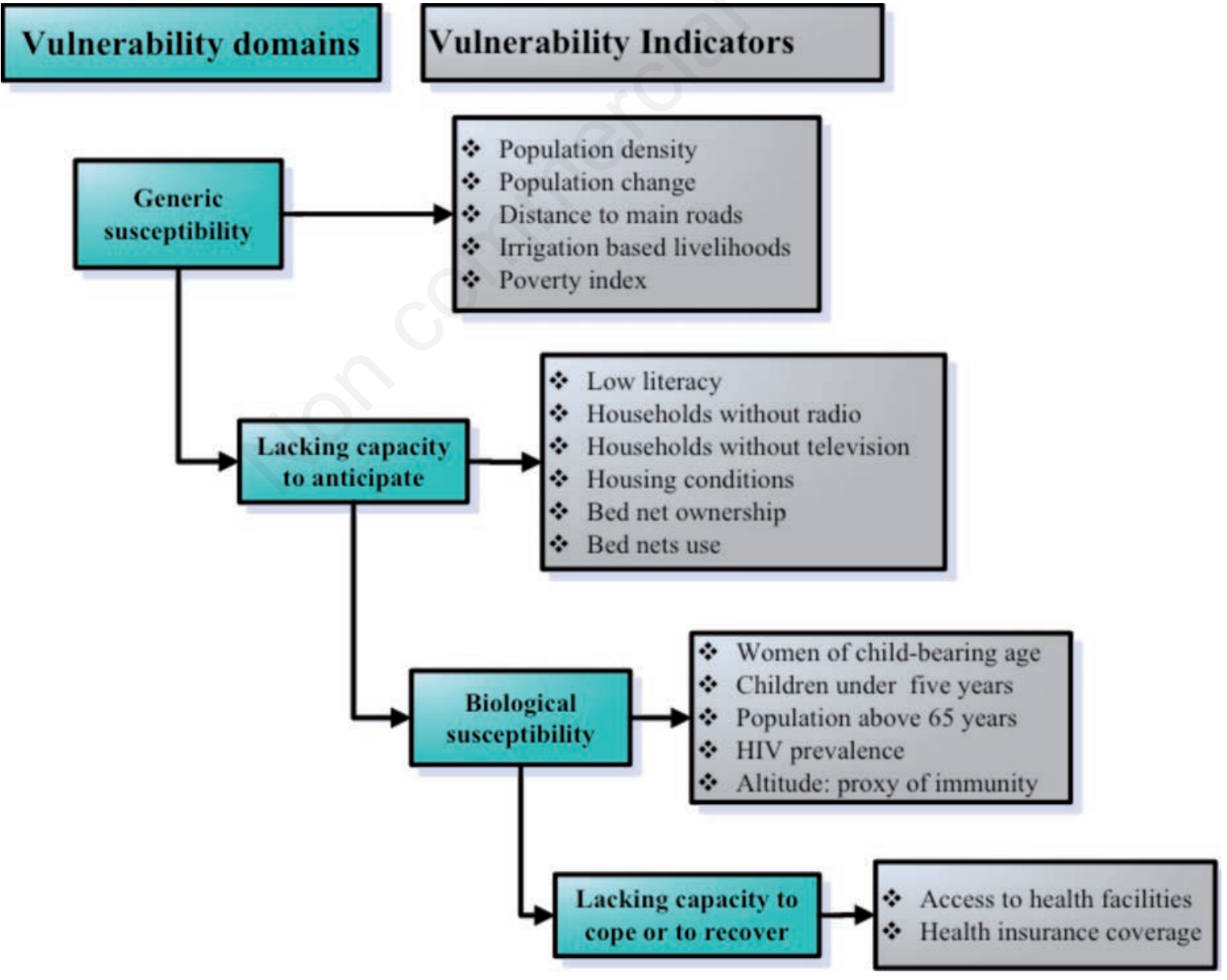

Figure 2. Adapted framework of social vulnerability to malaria. Based on Kienberger and Hagenlocher (2014). 


\section{Biological susceptibility}

As there is no available spatial dataset that measures immunity to malaria in Rwanda, we used altitude as a proxy for immunity to reflect prevailing levels of malaria endemicity. Apart from the long-term influences that climate and land use changes may have, malaria transmission above $2000 \mathrm{~m}$ in altitude would not be possible (Babu et al., 2004). Highland populations with low immunity become ill following their initial exposure to the malaria parasite, developing a febrile illness which may become severe (Snow et al., 1997). The immunity is defined as the host's ability to resist the pathogenic effect of a malaria infection. Some immunity is acquired in response to repeated exposure to infection (Cromley and McLafferty, 2012). Since previous exposure to malaria infection is required, immunity fails to develop in high altitude zones where malaria transmission is limited by low temperature. Thus, highland communities which are less exposed to mosquito bites would be more vulnerable to malaria infection than their counterparts in lowlands (Wandiga et al., 2010). In the lowlands where transmission intensity is high, the acquired immunity of people may be lost with an interruption to parasite exposure as result of seasonal malaria transmission, intensive interventions with insecticide, treated bed nets, or extended travel out of an endemic area (Baird, 1995).

Pregnant women are highly susceptible to malaria due to their lowered immunity (Van Geertruyden et al., 2005). As an example, during the 1998 malaria epidemic in Byumba highlands in Northern Rwanda, pregnant women were two to five times more likely to be admitted to the hospital for malaria than other adults (Hammerich et al., 2002). While young children are highly susceptible in endemic areas, the vulnerability to malaria extends to adults in epidemic-prone areas (Kiszewski and Teklehaimanot, 2004). Non-immune people such as populations moving into malaria areas are more vulnerable at any age (Bates et al., 2004). Stich et al. (2003) have found out that the elderly are highly susceptible to malaria, and have a higher risk of a severe course of malaria compared to the mid-age population. The risk of dying of the disease increases steadily with age. People aged over 65 years are almost 10 times more likely to die from the disease than those who are aged 18-35 (Checkley et al., 2012), as they lack immunity against the disease. An HIV infection increases the risk of malaria by impairing the immune response, thus decreasing the ability to withstand malaria infection (Verhoeff et al., 1999), and by reducing the drug's efficacy (González et al., 2012). High malaria prevalence rates among HIV positive pregnant women were also confirmed in Rwanda (Ladner et al., 2002), particularly in urban areas (Ivan et al., 2012, 2013).

\section{Capacity to anticipate mosquito bites}

The incidence of malaria is influenced by the lacking capacity to anticipate exposure to mosquito bites. This capacity relates to the level of protection measures, housing conditions, education level, and knowledge about malaria transmission and prevention, which lead to better use of malaria interventions (Appiah-Darkwah and BaduNyarko, 2011). Malaria health education given to pregnant women improved their knowledge about malaria, and enabled them to make effective decisions towards malaria prevention in Rwanda (Nishimwe and Kerr, 2012). However, the link between malaria and education may be explained by its role as a proxy for poverty. Furthermore, mass media communication (radio and television) play a strong role in malaria control, in ensuring that bed nets are properly used (Bowen, 2013).

Sleeping under bed nets is the most recommended protection method against malaria by the WHO (2011). In order for the bed nets to be effective they should sufficiently cover the bed, be re-treated with insecticide regularly, and be properly deployed every night (Janssen, 2005). Despite the declining malaria transmission, high numbers of host-seeking malaria vectors may be found indoors in rural areas in Rwanda, due to poor housing quality, which provides less protection against mosquitoes (Mwangangi et al., 2012). Malaria risk factors associated with housing conditions are: earth roofs, open eaves and windows, and poor wall construction materials (Graves et al., 2009). In addition to bed nets and indoor residual spraying interventions, efforts should also focus on improving housing conditions to prevent mosquito bites (Lwetoijera et al., 2013).

Table 1. Social vulnerability indicators.

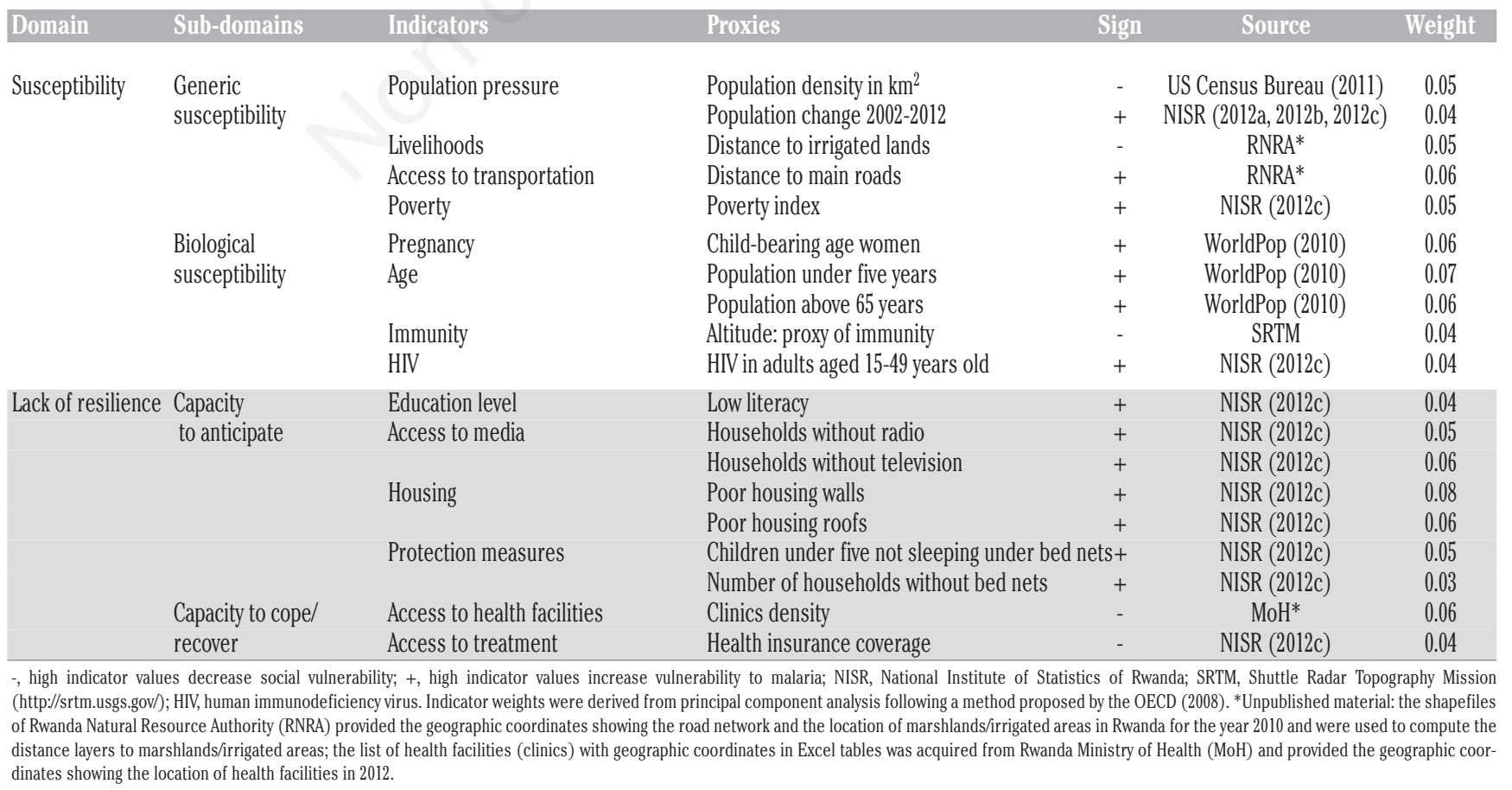




\section{Capacity to cope with/recover from malaria}

The capacity to cope with malaria is influenced by access to health infrastructure and effective treatment. According to the Roll Back Malaria Global Strategic Plan 2005-2015, ensuring prompt and timely treatment prevents most cases of uncomplicated malaria from progressing to a severe and fatal illness (Roll Back Malaria, 2005). To avoid malaria mortality, treatment must begin as soon as possible, generally within 24 hours after the onset of symptoms. Additionally, communities should be aware of the importance of seeking prompt diagnosis and treatment (Chanda et al., 2011).

To be able to provide quick access to healthcare services, effective and appropriate treatment should take into account poor rural populations who are poorly served by the healthcare system (WHO, 2000). However, poor families living in remote areas of Sub-Saharan Africa have less access to basic preventive measures for malaria control, and may live many kilometers away from the nearest healthcare facility (Onwujekwe et al., 2011). The long distance to a primary healthcare facility is among the impeding factors which delay the prompt diagnosis and timely treatment of malaria (Turuse et al., 2014). To respond to the community needs for prompt and effective treatment of malaria in Rwanda, the community-based health insurance programme commonly known as mutuelles de santé was established in 1999 by the Rwandan Government. This programme is a key component of the national health strategy for providing affordable universal healthcare (Government of Rwanda, 2010).

\section{Modelling regions of social vulnerability to malaria}

Spatial scale and the choice of the right reporting unit are a concern to medical geographers (Meade and Earickson, 2005). Lang et al. (2008) proposed the geon concept, which allows the modelling of homogenous regions of multi-dimensional phenomena - such as social vulnerability - independent of administrative units. Geons are defined as spatial objects that are delineated by regionalising gridded datasets, representing relevant social vulnerability indicators in a multidimensional indicator space. By applying an integrated geon approach (Lang et al., 2014), we create spatially exhaustive sets of units revealing the spatial pattern of social vulnerability to malaria. The geon approach has been successfully applied in previous studies, for instance to model social vulnerability to malaria in the East Africa region (Kienberger and Hagenlocher, 2014), where this study is also based. Figure 3 shows the key steps applied to model social vulnerability to malaria following the integrated geons concept at the national scale level in Rwanda.

As illustrated in Figure 3, the modelling process includes the conceptualisation of vulnerability to malaria infection, identification of social vulnerability domains and suitable indicators, acquisition of datasets, imputation of any missing value, and data transformation. After processing the indicators by interpolation and resampling, all indicator gridded values were normalised to an 8-bit value range (0-255) to compare the integrated indicator values between them. A correlation analysis was performed to determine the significance of correlations present among the indicators, and the output was checked for multi-collinearity, to remove the highly correlated indicators. The statistical weights extracted from PCA were assigned to single indicator layers; the indicators were integrated into Trimble eCognition Developer software to delineate homogeneous regions of social vulnerability through segmentation and regionalisation. A cartographic visualisation method was adopted to translate the social vulnerability index into a geographic map. ESRI ArcGIS10.2 software was used to map the final index of social vulnerability to malaria for each delineated unit.

\section{Data pre-processing: creating continuous surfaces}

Most of the data used was collected from the Demographic and Health Survey (DHS), and from different secondary data sources in Rwanda. Guided by the adopted vulnerability framework, relevant data for indicators was selected from the DHS database. Although the DHS data can be geo-referenced, the sampling method is not appropriate for spatial interpolation. Accordingly, a spatial interpolation methodology, developed by Larmarange et al. (2011), was adopted for generating the smoothed trends of DHS data using R statistical software. This method uses kriging and smoothing techniques to estimate the regional variations in accordance with the accuracy of the data of each zone. Other spatial gridded data (child-bearing aged women, population under five years, and elderly population) were downloaded from the WorldPop Project data repository (2010). These data are provided at continent level, with a spatial resolution of $100 \times 100 \mathrm{~m}$, and have been clipped to the national boundary of Rwanda.

To ensure consistency, all spatial datasets were resampled to $500 \mathrm{x}$ $500 \mathrm{~m}$ cell size, which both reflects the small size of Rwanda and takes into account the average size of sub-administrative units. ESRI ArcGIS 10.2 software was used to alter the generated raster layers by changing their cell sizes to 500 meters, while their spatial extent remained the same. Resampling is a normal procedure for (automatically) adjusting one or more raster datasets to ensure that the grid resolutions of the used raster datasets match when carrying out combination operations (de Smith et al., 2015).

Population data for Rwanda (at $100 \mathrm{~m}$ resolution) was acquired from the US Census Bureau (2011) and used to analyse population change between 2002 and 2012. Kernel density estimation was applied using ArcGIS 10.2 software (ESRI, Redlands, CA, USA) to generate the raster map of population change at the country level, with a spatial resolution of 500 meters. Spatial data for irrigated lands was collected from the Rwanda Natural Resources Authority. The assumption was that social vulnerability to malaria may be higher in populations near the irrigated farming communities than in populations far away from irrigated lands.

Despite the intense malaria interventions with insecticide-based control in Rwanda, we believe that people living in the proximity of irrigation infrastructure are potentially exposed to an increased risk of malaria infection. This is due to changes in ecological and hydrological conditions that lead to increased vector abundance (Baeza et al., 2013). Kibret et al. (2014), who revealed that the irrigation schemes intensify malaria transmission due to poor water management in irrigation areas, support this theory.

Kernel density estimation was also applied to model the relative density of clinics in each area using the health centers' geographic coordinates, collected from the Ministry of Health. The least accumulative cost distance for each cell to the nearest road network was computed using cost distance tools in the ArcGIS 10.2 software. The cost distance tool creates an output raster (cost distance to road) in which each cell is assigned the accumulative traveling cost based on slope to the closest road network (de Smith et al., 2015).

\section{Data pre-processing: normalisation and multicollinearity analysis}

To allow the integration and comparison of different indicator layers, linear min-max normalisation was applied (Nardo et al., 2005):

$$
v^{\prime}=\frac{v-\min }{\max -\min } * 255
$$

In the above equation $v^{\prime}$ represents the normalised indicator, $v$ is the 
old indicator value, and the max and min values derive from the old value range. To detect multi-collinearity in the datasets, the Pearson correlation coefficients and variance inflation factors (VIF) were computed (OECD, 2008), whereby Pearson's $r$ greater than 0.92 (Field, 2005) and/or VIF values greater than 5 indicate multicollinearity. When examining the results of the multicollinearity analysis only one value greater than the threshold was found, indicating high collinearity between the poverty index and radio ownership. However, since both indicators influence malaria incidence differently, both indicators were kept in the analysis, especially since the variance inflation factor (VIF) values were acceptable for all indicators.

Data pre-processing: identifying indicator weights using principal component analysis

A principal component analysis (PCA) was used to assign weights to indicators (Pattanaaik et al., 2008). Principal component analysis was selected since it has the advantage of determining weights that reflects

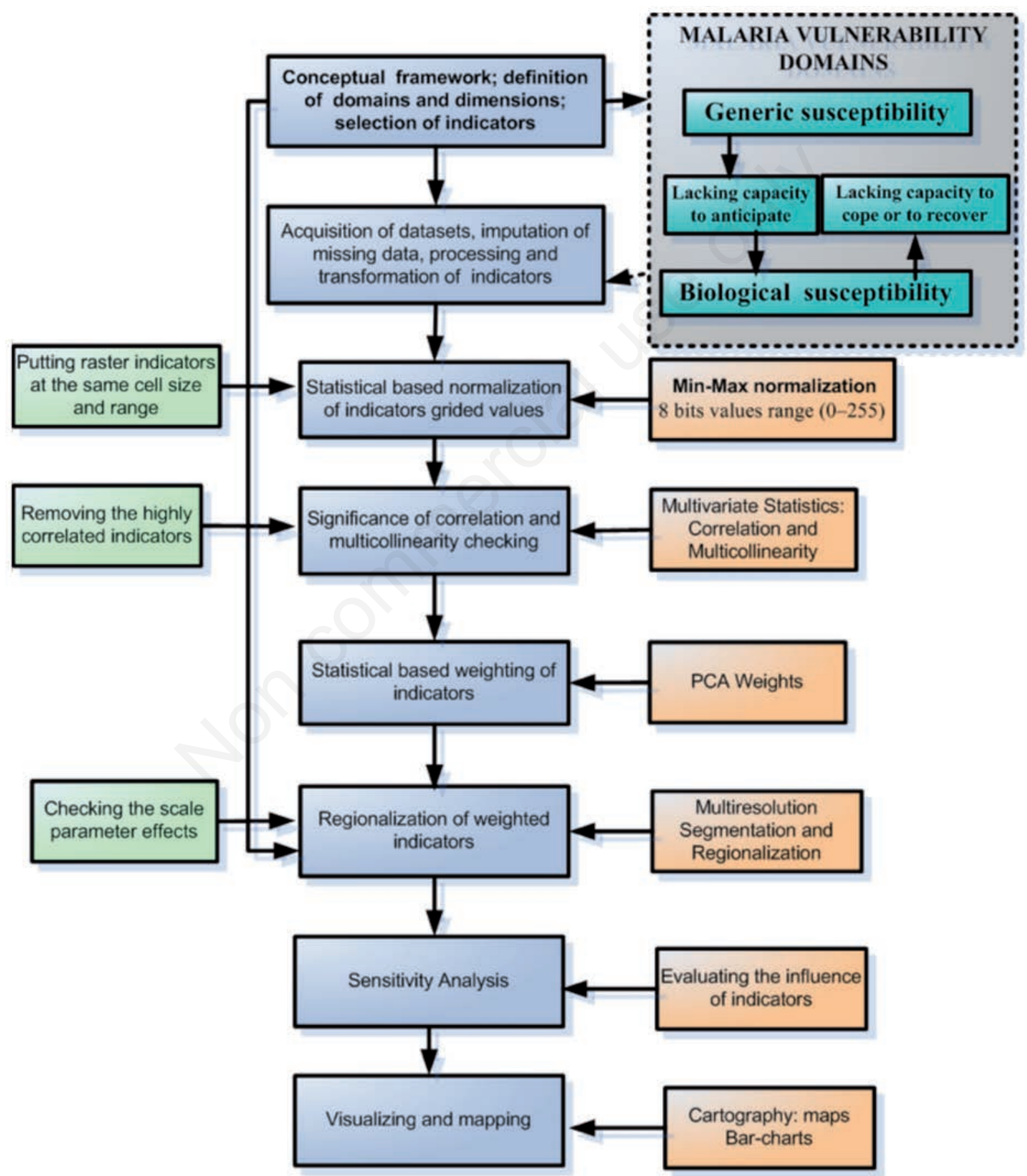

Figure 3. Workflow showing the individual modelling stages. Based on Kienberger and Hagenlocher (2014). 


$$
V U=\sum n \cdot \frac{\mathrm{D}}{\mathrm{N}}
$$

the largest variation in original indicators (Slottje, 1991). Moreover, we
used PCA since it was difficult to find experts for a participatory weighting of indicators. Before running the PCA, Kaiser-Meyer-Olkin (KMO) statistics and a Bartlett's test were performed to examine the data's suitability for PCA. High KMO values $(>0.6)$ indicate that the PCA may be useful (Vines, 2000). For this study, the KMO value of 0.727 indicates that the selected indicators were suitable for PCA. The extracted two components accounted for $91.5 \%$ of the cumulative variance of the raster input layers. Indicators were weighted with the proportion of variance explained by each component, taking into account the total variance of the component on which each indicator is heavily loaded (Abson et al., 2012b). Only the principal components with eigenvalues larger than one, which individually contribute to the overall variance by more than $10 \%$ of the rotated squared loadings, and cumulatively to more than $60 \%$, were retained (OECD, 2008). The principal component scores together with the factor loadings provide information pertaining to the relative level of social vulnerability (scores) and the underlying drivers of vulnerability (Abson et al. 2012a, 2012b). The weights were obtained from the PCA derived component eigenvalues, and then normalised by the squared factor loadings, which are the portions of the variance explained by indicators; subject to the condition that the sum of the squared weights is equal to one (Vyas and Kumaranayake, 2006; Hudrliková, 2013). The weight for each indicator is displayed in Table 1.

\section{Data pre-processing: delineating homogeneous vulnerability regions}

After resampling all indicators to the same cell size and assigning the weights to the indicator layers, the datasets were integrated into Trimble eCognition Developer software for delineating regions of social vulnerability through regionalisation. The multi-resolution segmentation algorithm (Baatz and Schäpe, 2000) was used for the regionalisation of the spectral reflectance of the indicator values. To parameterise the segmentation algorithm we used the Estimation of Scale Parameter tool (ESP2), developed by Drãgut et al. (2014). This approach takes into account the local variance of object heterogeneity. The ESP2 tool was used to iteratively generate the image-objects at multiple scale levels in order to calculate the local variance for each scale. For each delineated region, a vulnerability domain value (generic susceptibility, lacking capacity to anticipate, biological susceptibility, and lacking capacity to cope) was calculated using the weighted vector magnitude, as shown in the following equation:

$$
\text { BioSUS }=\sqrt{\mathrm{w}_{1} \mathrm{SUS}_{1}^{2}+\mathrm{w}_{2} * \mathrm{SUS}_{2}^{2}+\mathrm{w}_{3} * \mathrm{SUS}_{3}^{2}+\mathrm{w}_{4} * \mathrm{SUS}_{4}^{2}}
$$

In equation 2, BioSUS refers to the biological susceptibility domain. The value of biological susceptibility for each delineated region is equal to the square root of the sum of the weighted squared indicator values, representing the vector magnitude of each region (Kienberger et al., 2009). $w$ represents the weight for a given indicator of biological susceptibility, and represents the normalised indicator value ( $v$ ') for the biological susceptibility domain. The final vulnerability index is equal to the sum of vulnerability domain weighted values, divided by the number of indicators in each domain. This allows the domains that group together a higher number of indicators to have a higher weight, as shown by the following formula:
In equation $3, V U$ represents the vulnerability index score; $n$ is the number of indicators for a given domain; $D$ is equal to the value of aggregated weights for each vulnerability domain (generic susceptibility, lacking capacity to anticipate, biological susceptibility, and lacking capacity to cope); and $N$ refers to the total number of indicators used. From the 19 indicators that were identified in literature, five indicators were assigned to the generic vulnerability domain, seven indicators to lacking capacity to anticipate, five indictors to biological susceptibility, and two indictors to the lack of capacity to cope with or recover from malaria. The aggregation approach of the social vulnerability index used in this study slightly differs from Kienberger and Hagenlocher (2014), because it takes into account the number of indicators for each domain. Another key difference is that the weights were assigned from PCA, whereas Kienberger and Hagenlocher (2014) used expert weights. The contribution of the separate indicators to the social vulnerability score was calculated for each delineated unit, to evaluate the composition of homogeneous regions of vulnerability, by decomposing them into the underlying indicators (Hagenlocher, 2013; Kienberger $e t$ al., 2013a).

\section{Results and Discussion}

\section{Aggregated indicators and regions of social vulnera- bility to malaria}

The final index of social vulnerability to malaria is presented in Figure 4, which shows the generic and biological susceptibility to not withstanding malaria infection, the lack of capacity to anticipate exposure to mosquito bites, as well as the lacking capacity to cope with or recover from malaria infection. The homogeneous regions of social vulnerability to malaria outlined herein were modelled independently of the spatial distribution of the disease.

High values of social vulnerability to malaria are found in the highlands, especially along the Congo-Nile Crest, and in the very eastern lowlands. Except for the highly vulnerable area in the very East, the other most vulnerable regions are generally located in malaria epidemic prone-areas, which are characterised by unstable malaria transmission. The populations in these regions are most vulnerable to malaria epidemics due to a low level of immunity (Gascon et al., 1988). Malaria epidemics often occur in these areas, overwhelming the coping ability of medical facilities (Hay et al., 2002). In addition, low values of social vulnerability are found near Kigali City, in the eastern lowlands, and in the central plateau, particularly near the urbanised areas. This finding is supported by Richmond et al. (2015), whose study highlighted the capital city of Kigali and major urban centers with low values of vulnerability, in stark contrast to the rest of the country. This concentration of wellbeing in urban centres exemplifies the well known geographic concepts of core and periphery and distance decay (Baldwin and Forslid, 2000). The eastern lowlands are generally suitable for malaria transmission. However, since malaria is also sensitive to socioeconomic factors and health interventions, climate suitability in lower lands can be counterbalanced by improved wellbeing, effective malaria control, and intense interventions.

High index scores are found in highlands along the Congo-Nile Crest and in the very eastern lowlands. This finding is in agreement with a recent study by Richmond et al. (2015), who found highly vulnerable areas in the 
western districts near the Gishwati-Mukura and Nyungwe National Parks. These regions are frequently affected by food insecurity due to infertile soil and market access. As such, poor households live in small crowded homes on small plots of land and lack income diversification. Except for the highly vulnerable area in the very East near the Tanzanian border, the other most vulnerable regions are located in malaria epidemic-prone areas, charac- terised by unstable transmission. In addition, low levels of social vulnerability are observed near the urbanised areas of Kigali City, on the central plateau, and in the eastern lowlands. As malaria is also sensitive to socioeconomic factors and health interventions, climate suitability in these areas can be counterbalanced by improved wellbeing, as well as effective and intense malaria interventions.

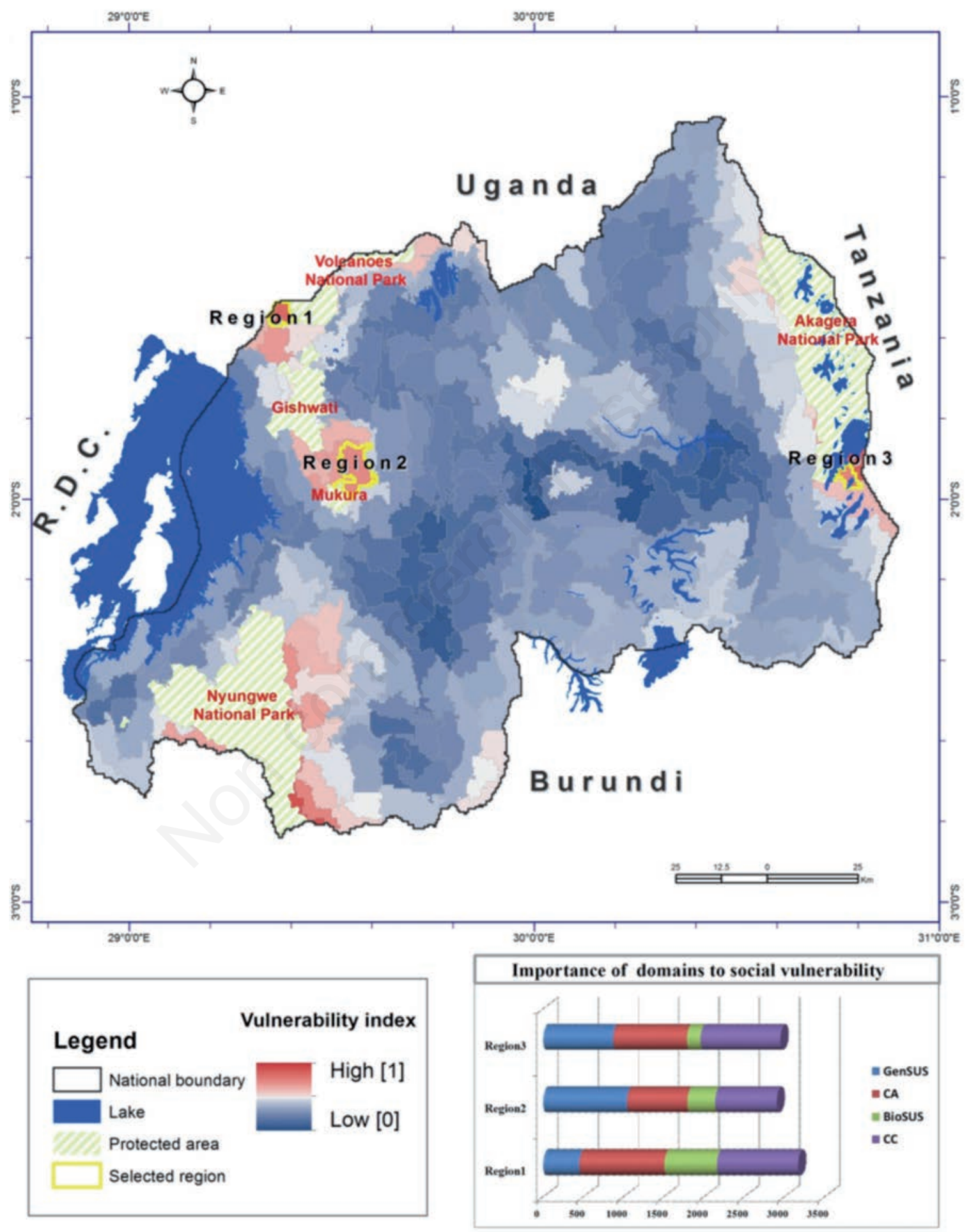

Figure 4. Homogeneous regions of social vulnerability to malaria in Rwanda. GenSUS, generic susceptibility; CA, capacity to anticipate mosquito bites; BioSUS, biological susceptibility; CC, capacity to cope with malaria. 
The high level of social vulnerability to malaria in the highlands exacerbates the susceptibility of populations with low immunity to epidemic malaria. The remoteness of the most vulnerable areas near the borders also makes it difficult to provide adequate and appropriate health services to the resident populations. Their vulnerability is exacerbated by crossborder migrations, where malaria is imported from elsewhere, rather than linked to the location (WHO, 2011). Despite the limited long-term migrations in Rwanda, temporary migrations have been reported in the last five years (Blumenstock, 2012); and cross-border movements are responsible for malaria transmission (USAID, 2013). Since malaria is not likely to be diagnosed early, asymptomatic malaria may prevail among moving people, who may become a reservoir for local transmission. To tackle this issue properly, adequate health care facilities and effective treatment should be provided to moving people in the most vulnerable areas near international borders. This may be an efficient and relevant malaria intervention method, to eliminate malaria in these regions. Malaria elimination policies and strategies therefore need to identify migrant streams with the potential of spreading malaria, and target the appropriate interventions in the most vulnerable regions, to prevent epidemic malaria in the Rwandan highlands.

Region 1 in the very North West is highly vulnerable, mainly because of the lacking capacity to anticipate and recover from malaria. Region 2 along the Congo-Nile Crest in Ngororero District requires more interventions that could reduce its generic susceptibility and limited coping capacity. For the vulnerable region 3 near the Tanzanian border, more attention should be paid to the generic susceptibility indicators: lacking capacity to anticipate and recover from malaria. It is surprising that regions 1 and 2 are identified for priority interventions in the areas where malaria transmission would be absent or limited by low temperature. However, the 2010 demographic and health survey in Rwanda confirmed some pockets of high malaria prevalence rates in these areas (according to the map shown in Figure 1). This may be associated with the socioeconomic conditions that drive the vulnerability within the local communities, rather than the climate suitability and exposure to mosquitoes. The results highlight the importance of using a socioeconomic approach to target malaria interventions in Rwanda. Compared to the East African Regional scale, the results of social vulnerability modelling by Kienberger and Hagenlocher (2014) are only valid at regional scale. Moreover, these results are not suitable for providing a detailed and heterogeneous social vulnerability map, which is particularly relevant for small countries. The results from the regional scale modelling approach by Kienberger and Hagenlocher (2014) need to be interpreted with caution when translated to an isolated national scale, due to varying multi-source data quality and accuracy between regions in the East Africa Community countries. For instance, in this study we were able to identify a spatial heterogeneity of the hidden social vulnerability to malaria in Rwanda, which the regional scale modelling was not able to identify in such detail, due to its relative scaling for the entire EAC region.

Validation of results is still a critical issue in index-based spatial vulnerability (and risk) assessments. This is primarily linked to the fact that vulnerability is latent and multi-dimensional by definition, and thus cannot be measured directly. Furthermore, (social) vulnerability is only one component of risk, which poses the question of how a single aspect (vulnerability) can be validated, when it is embedded in a larger whole (risk). Hagenlocher and Castro (2015) validated an integrative malaria risk index in Tanzania using infection prevalence, for instance. However, such an approach has no validity in the present case, due to fact that vulnerability represents one component of risk only. Therefore, the validation of index-based vulnerability maps requires detailed empirical analysis, which is currently not available for this specific context and the required spatio-temporal scales. Fekete (2009) highlights that vulnerability assessments could be validated using an independent second dataset, which, however, is not available in this case. Hence, we carried out a technical validation using approaches of sensitivity and uncertainty analysis, following the method proposed by Lung et al. (2013). This involved calculating a set of alternative vulnerability indices by discarding one indicator at a time, while keeping all other settings the same (normalisation, weighting, aggregation). The box plots in Figure 5 show the influence of each indicator on the final vulnerability index.

The results from Figure 5 show that some vulnerability indicators, like poor housing, wall materials, television ownership, clinic density, distance to main road, poverty rate, distance to irrigated areas, and elevation in meters (immunity), have an excessive influence on the final vulnerability index score. Conversely, other indicators, such as population under five years of age, population changes, HIV prevalence, and population density are the less influential indicators on the final vulnerability index.

\section{Domains of social vulnerability to malaria}

The inclusion of spatially explicit indicators in vulnerability assessments aids decision makers in identifying drivers of social vulnerability to malaria in specific areas. The resulting holistic social vulnerability assessment can empower decision makers in targeting mitigation and adaptation efforts in areas where social vulnerability is highest, and in focusing on factors that most impact vulnerability (Frazier et al., 2014). In addition to the final index of social vulnerability to malaria, the spatial heterogeneity of social vulnerability to malaria at domain level is illustrated in Figurse 6 and 7. These domains are generic susceptibility (Figure 6A), biological susceptibility (Figure 6B), lacking capacity to anticipate (Figure 7A), and lacking capacity to cope with or recover from malaria infection (Figure 7B). By depicting social vulnerability in different domains, it was revealed that the high social vulnerability does not necessarily imply that values for all four domains of vulnerability to malaria are high. By exploring the relative share of contributing vulnerability indicators, depicted in bar charts, it is possible to answer the spatial question of what needs to be done where? For instance, the high values of generic susceptibility are found in the mountainous areas, particularly in the Ngororero and Nyamagabe Districts, in remote rural areas of the eastern lowlands, and in the southern part of Rwanda - the Gisagara District. The generic susceptibility of region 1 in Ngororero District may be associated with poverty, high population density and poor road infrastructure. For the most vulnerable region 2 in Gisagara District, the major influencing factors of social vulnerability include poverty, poor road infrastructure, and irrigation-based livelihoods. Other studies in a neighboring district of Gisagara (Bugesera District in southeastern Rwanda) have blamed poverty to be the leading factor of malaria incidence. These studies suggested that improving household income and living conditions for poor families should be the first step towards the development of effective and targeted interventions, to further reduce malaria transmission in the rural areas of Rwanda (Ingabire et al., 2014, 2015).

The vulnerability of region 2 within Gisagara district may be exacerbated by cross-border migrations to Burundi, where malaria is also endemic. The generic susceptibility of region 3 in the East, near Akagera National Park, is explained by population density, poor road infrastructure, as well as the presence of irrigable lands, water bodies (lakes and rivers), wetlands and large valleys. This region is already characterised by high malaria endemicity, and thus an increased risk to malaria infection.

Ijumba and Lindsay (2001) claimed that the introduction of crop irri- 
gation has little impact on malaria in the areas of stable transmission, therefore leading to reduced vulnerability despite an increase in exposure to malaria vectors. The main explanation is the positive socio-economic impact, leading to a greater use of bednets, better access to improved healthcare and fewer infective bites in irrigation communities (Ijumba and Lindsay, 2001). Nevertheless, the increased numbers of malaria vectors following irrigation definitely leads to an increased malaria occurrence in areas of unstable transmission in the highlands of Rwanda, where people have little or no immunity to malaria parasites (ljumba and Lindsay, 2001). The population growth rate in Rwanda highlands has led to an increased demand for food and wetlands reclamation for irrigated crops (Nabahungu and Visser, 2013), and consequently an increased vulnerability to malaria infection (Bizimana et al., 2015).

The densely populated highlands and urbanised areas are biologically most susceptible to malaria (Figure 6B). The biological susceptibility in region 1 is mainly related to demographic pressure, such as a high number of children under five years of age, high number of old people, high number of child-bearing aged women, and high HIV prevalence. In the highlands in region 3 and region 2, the high number of women of childbearing age and high number of old people are combined with the low immunity to exacerbate the biological susceptibility to malaria. While generic susceptibility is high in both highland and lowland areas, the biological susceptibility is generally high in highlands and urbanised areas, where malaria transmission is very low and unstable, causing a lack of immunity in local populations. This finding is similar to the findings of Kienberger and Hagenlocher (2014), which highlighted medium to high levels of social vulnerability in Kigali and in the highland areas that are affected by epidemic malaria outbreaks.

Figure 7 illustrates the lack of resilience, which relates to the lacking capacity of populations to respond to and absorb the negative impacts of malaria, as a result of the lacking capacity to anticipate, respond to, and recover from malaria infection. In terms of lack of capacity to anticipate mosquitoes, higher values of social vulnerability are also found in the highlands, particularly in the very South near Nyungwe National Park, in the North within the Burera District, and in the very East near the border with Tanzania (Figure 7A). The most vulnerable region in terms of lacking resilience, region 1 in the South, has very limited

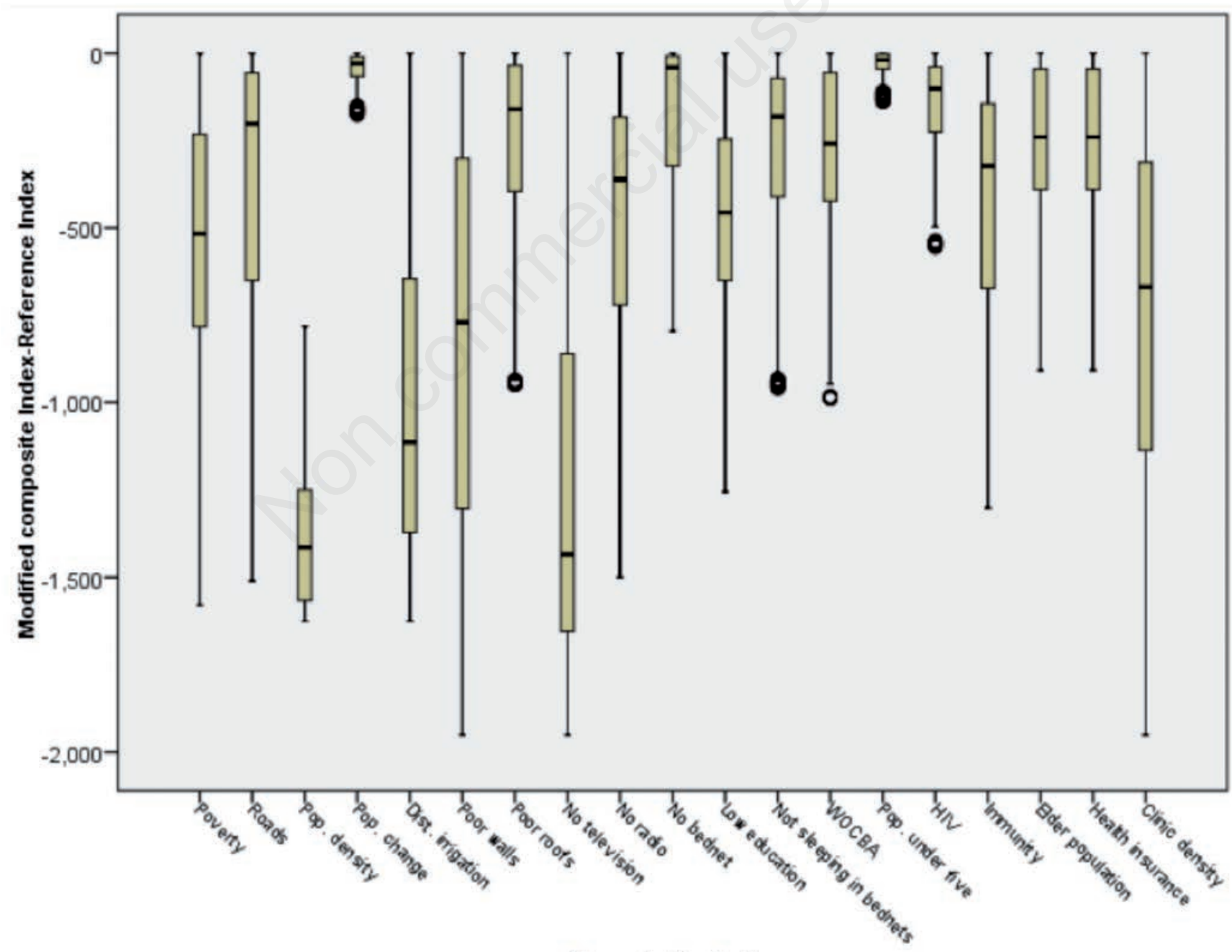

Discarded indicator

Figure 5. Box plots showing the influence of single indicators on final composite index. 

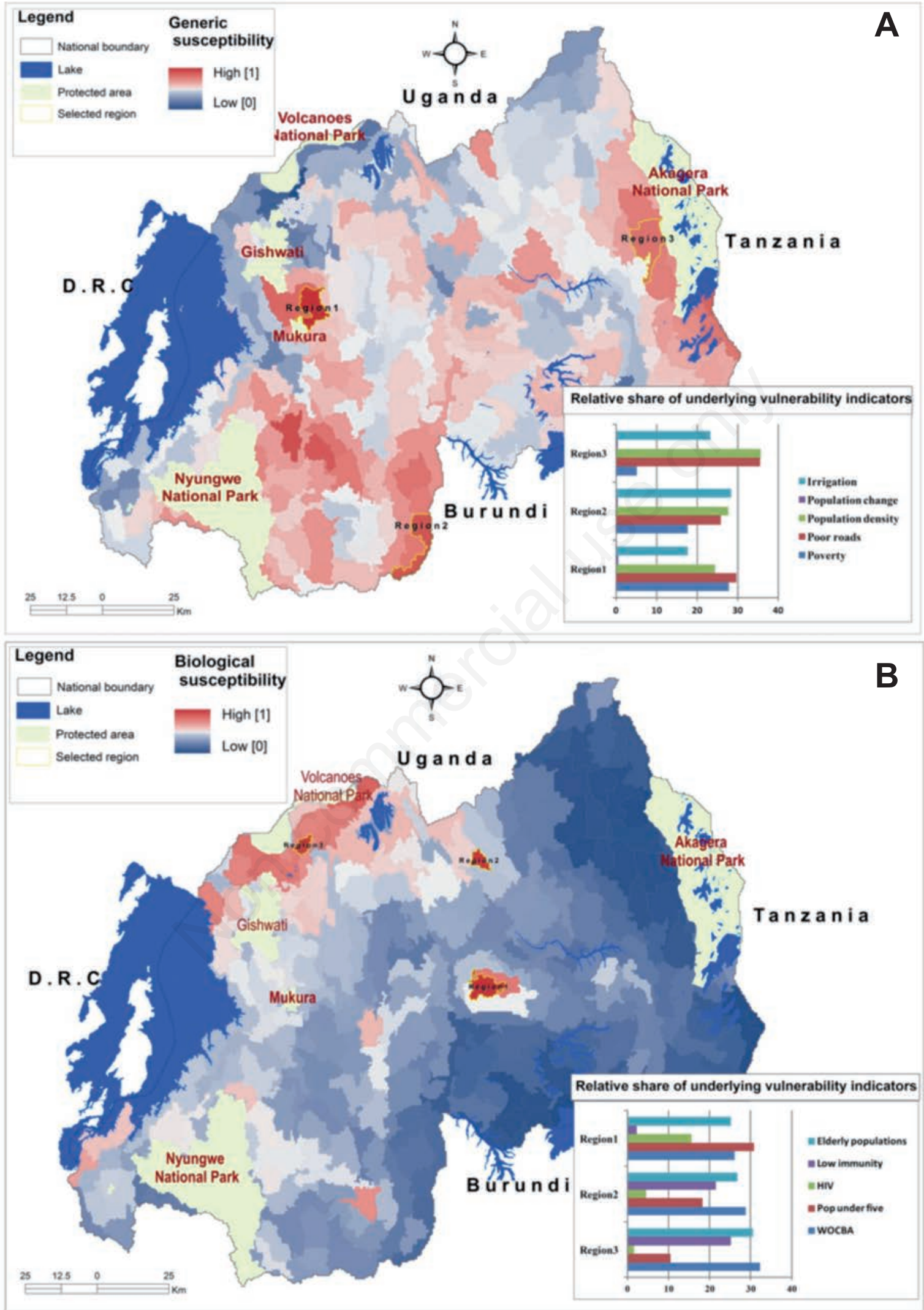

Figure 6. Generic (A) and biological (B) susceptibility to malaria in Rwanda. 

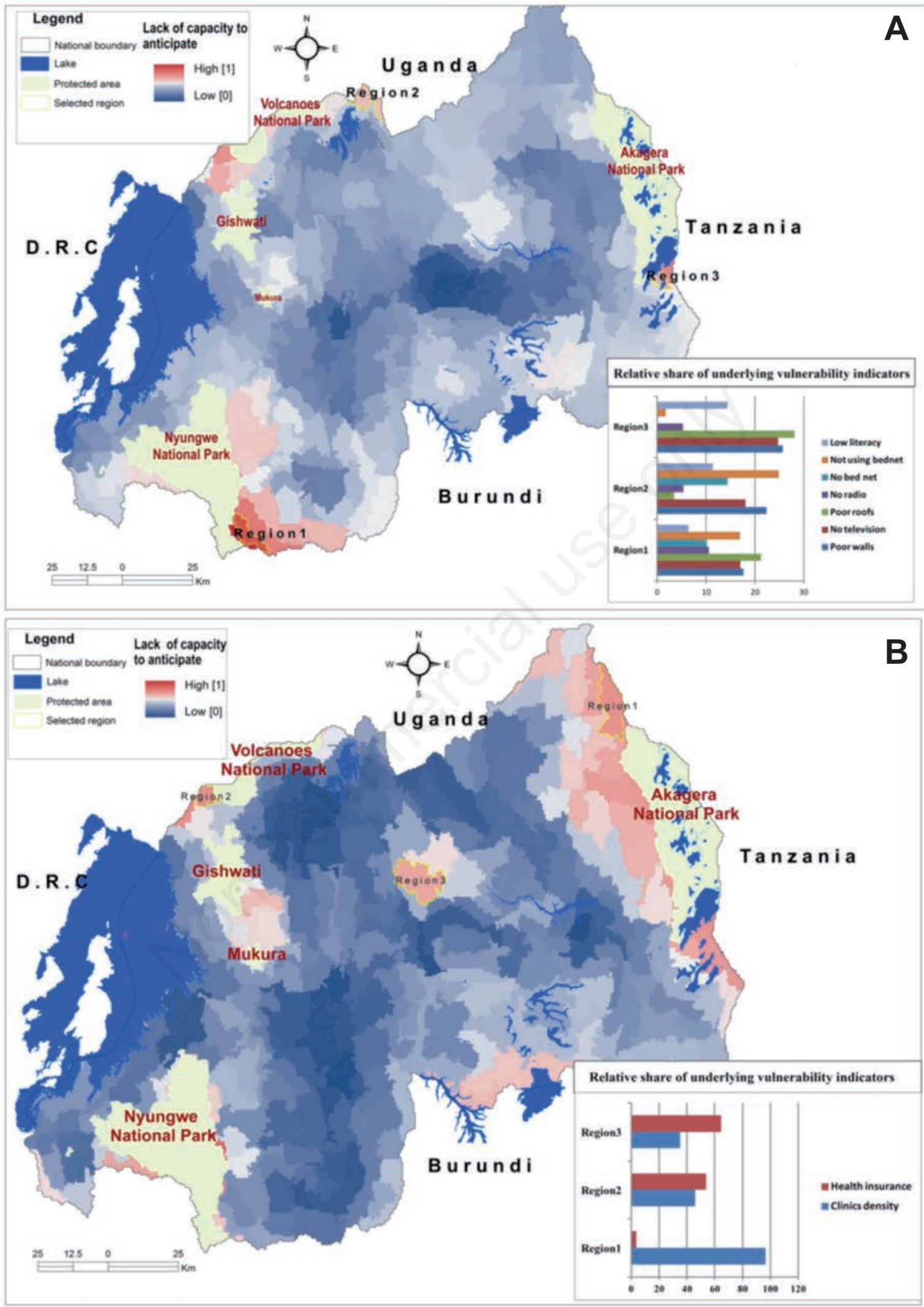

Figure 7. Lacking capacity to anticipate (A) and cope (B) with malaria infection in Rwanda. 
capacity to anticipate, due to poor housing conditions, limited access to communication means, a low literacy rate, and a low rate of bed net ownership and use. The low rate of bed net use in remote rural areas of Rwanda may be aggravated by the loss of fabric integrity and declining bio-efficacy of long lasting insecticide traited nets (LLITN), and therefore foster the loss of protection from man-vector contacts (Hakizimana et al., 2014). The most influencing indicators of social vulnerability for region 2 in the North near the Ugandan border are almost similar to those of region 1 in Nyaruguru District, because both regions are located in the highlands.

Due to population pressure and stressed land resources, lowly immune highland populations move from Burera to settle in malaria endemic areas of the Eastern lowlands, where they are more susceptible. For instance, the 2012 census in Rwanda classifies Burera among the districts with the highest number of native-born population residing elsewhere. Among the migrants living in Nyagatare District, 22\% were born in Burera District (NISR, 2012a). Moreover, worker migrants seasonally move from Burera to Uganda to take advantage of economic opportunities. The high mobility of populations in Burera highland District coupled with the limited capacity to anticipate mosquito bites may exacerbate the social vulnerability to malaria. Thus, the recent malaria occurrence in this highland zone may be explained by the interplay of socioeconomic factors such as population pressures, land use change, poverty, population movements and migrations, and local climate change (Henninger, 2013a, 2013b).

Social vulnerability in region 3 , in the very East by the border of Tanzania, is only associated with poor housing quality, limited access to media communication, and a low literacy rate. Effective malaria interventions in this region should thus focus on social wellbeing, housing improvement and enhanced community awareness about malaria transmission and prevention. This finding is supported by Kateera et al. (2015) who concluded that efforts to reduce transmission and eliminate malaria locally should focus on investments in programmes that improve housing structures, by limiting indoor malaria transmission, for instance by making insecticide-treated bed nets and indoor residual spraying implementation more effective in Rwanda.

In terms of lack of capacity to cope with or to recover from malaria infection, the highlands and remote rural areas near the protected forests are characterised by less coping capacity (Figure 7B). For the highly vulnerable region 1 in the North East within Nyagatare District, the limited number of health facilities calls for improved interventions. While community-based health insurance in Rwanda is an effective tool for achieving universal access to health treatment in the poorest rural settings (Lu et al., 2012), low coverage of health insurance may limit the access to effective malaria treatment in the most vulnerable region 2 (Figure 7B) near Volcano National Park, and in region 3 within Rulindo District. The poorest groups are increasingly included in the health insurance system (Zeekaf, 2014), and it is frequently stated that universal coverage has almost been reached (Nyandekwe et al., 2014). However, a recent study revealed that one-third of the poorest groups are still not insured in Rwanda. Specifically, the health insurance scheme in Rwanda should focus on improving the availability of drugs on all health care access levels (especially the lowest levels), and making the nation-wide access policy work in practice (Zeekaf, 2014).

The results of this study bear implications for public health policy and decision making in malaria control in Rwanda. By revealing homogeneous regions of social vulnerability to malaria, including an analysis of underlying factors, this approach helps to the answer the question of what needs to be done where? The utilised geon approach enabled the depiction of the spatial heterogeneity of social vulnerability to malaria. The spatially explicit modelling of social vulnerability is a well-timed support to the national integrated malaria initiative for malaria reduction. It can help to improve the efficacy, effectiveness, and sustainability of malaria interventions through advocacy, social mobilisation, and inter-sector collaboration, to optimise the allocation of limited resources and health infrastructure.

The applied framework comes along with some challenges, however. Firstly, information related to the extent and coverage of IRS campaigns was not available, and thus not integrated into the vulnerability assessment. If this information was available for the entire country, and integrated into the modelling process, uncertainties in social vulnerability could be further reduced. Furthermore, some indicators such as social networks, migration, and behavioral change are difficult to measure quantitatively, and are therefore not considered in this research. Due to the absence of expert-based weights, indicator weights were assigned based on principal component scores and factor loadings from PCA, since both indicator weighting approaches were found to achieve similar outputs (Hagenlocher et al., 2013).

Despite the challenges highlighted above, the novelty of this research is based on the fine spatial scale and better quality of data available in Rwanda for revealing heterogeneous and hidden social vulnerability to malaria in a small country. For instance, we used high-resolution gridded surface layers of $500 \times 500 \mathrm{~m}^{2}$, compared to $10 \times 10 \mathrm{~km}^{2}$ used by Kienberger and Hagenlocher (2014) at East Africa Community regional scale. By using high resolution data, this paper advances the previous work in spatially informing decision-makers on heterogeneous and hidden social vulnerability to malaria in Rwanda, which cannot be modelled at East Africa Community regional scale. Moreover, new indicators such as population density and distance to irrigation areas were used as additional indicators for generic susceptibility, while only two indicators were integrated by Kienberger and Hagenlocher (2014). In the capacity to anticipate vulnerability domain, we extended the number of indicators to include information on access to communication media (radio and television) and housing conditions in terms of wall and roof materials. In the capacity to cope vulnerability domain, health insurance coverage was used instead of number of dependents to depict the lacking capacity to cope with malaria infection. Further research can be combine the presented maps of social vulnerability to malaria with the probability of an infective mosquito bites from EIR towards malaria risk assessment in Rwanda as recently implemented by Hagenlocher and Castro (2015) in Tanzania.

\section{Conclusions}

The spatial modelling approach using integrated geons, as implemented in this research, is a useful policy tool for identifying areas of concern in terms of both relative levels and underlying factors of social vulnerability to malaria. It provides a spatially explicit measure of social vulnerability that may help public health planners and decision-makers to tackle malaria, applying a socioeconomic perspective. This integrated modelling approach provides new insights, adding value to existing malaria elimination strategies that solely focus on climate and environmental factors of malaria transmission. Without understanding the social vulnerability and the response capacity of each region, targeting appropriate interventions may not lead to valuable outcomes. By integrating multi-source spatial indicators, the results provide meaningful information about social vulnerability aspects in specific locations. They not only indicate which areas are the most vulnerable, but also which factors mostly drive that vulnerability, according to a statistical analysis. This study also emphasised the need for socioeconomic considerations in the 
malaria elimination in Rwanda. The results from this research can help target the appropriate interventions to reduce the susceptibility of exposed host populations, and improve community resilience. Interventions to support socioeconomic development in the most vulnerable areas are necessary for eliminating malaria through different channels. Such interventions could provide highly effective and sustainable responses, aiding malaria elimination in the long term.

\section{References}

Abson DJ, Dougill AJ, Stringer LC, 2012a. Spatial mapping of socio-ecological vulnerability to environmental change in Southern Africa. Sustainability Research Institute, School of Earth and Environment, The University of Leeds, Leeds, UK.

Abson DJ, Dougill AJ, Stringer LC, 2012b. Using principal component analysis for information-rich socio-ecological vulnerability mapping in Southern Africa. Appl Geogr 35:515-24.

Alegana VA, Wright JA, Pentrina U, Noor AM, Snow RW, Atkinson PM, 2012. Spatial modelling of healthcare utilisation for treatment of fever in Namibia. Int J Health Geogr 11:6.

Appiah-Darkwah I, Badu-Nyarko SK, 2011. Knowledge of malaria prevention and control in a sub-urban community in Accra, Ghana. Int J Trop Med 6:61-9.

Baatz M, Schäpe A, 2000. Multiresolution segmentation - an optimization approach for high quality multi-scale image segmentation. In: Strobl J, Blaschke T, Griesebner G, eds. Angewandte Geographische Informationsverarbeitung. Wichmann, Heidelberg, Germany, pp $12-23$.

Babu CJ, Nair AS, David BV, 2004. Handbook of malaria. Disease, its vectors and management. Namrutha Publications, Chennai, India.

Baeza A, Bouma MJ, Dhiman RC, Baskerville EB, Ceccato P, Yadav RS, Pascual M, 2013. Long-lasting transition toward sustainable elimination of desert malaria under irrigation development. P Natl Acad Sci USA 110:15157-62.

Baird JK, 1995. Host age as a determinant of naturally acquired immunity to Plasmodium falciparum. Parasitol Today 11:105-11.

Baldwin RE, Forslid R, 2000. The core-periphery model and endogenous growth: stabilizing and destabilizing integration. Economica 67:307-24.

Bates I, Fenton C, Gruber J, Lalloo D, Medina LA, Squire SB, Theobald S, Thomson R, Tolhurst R, 2004. Vulnerability to malaria, tuberculosis, and HIV/AIDS infection and disease. Part I: determinants operating at individual and household level. Lancet Infect Dis 4:267-77.

Berg A, Patel S, Aukrust P, David C, Gonca M, Berg ES, Dalen I, Langeland N, 2014. Increased severity and mortality in adults coinfected with malaria and HIV in Maputo, Mozambique: a prospective cross-sectional study. PLoS One 9:e88257.

Birkmann J, Cardona OA, Carreno L, Barbat A, Pelling M, Schneiderbauer S, Kienberger S, Keiler M, Zeil P, Welle T, 2013. Framing vulnerability, risk and societal responses: the MOVE framework. Nat Hazards 67:193-211.

Birkmann J, Wisner B, 2006. Measuring the un-measurable. The challenge of vulnerability. United Nations University, Institute for Environment and Human Security, Bonn, Germany.

Bizimana JP, Twarabamenye E, Kienberger S, 2015. Assessing the social vulnerability to malaria in Rwanda. Malaria J 14:2.

Blumenstock JE, 2012. Inferring patterns of internal migration from mobile phone call records: evidence from Rwanda. Inf Technol Dev 18:107-25.
Borderon M, 2013. Why here and not there? Developing a spatial risk model for malaria in Dakar, Senegal. In: Cutter S, Corendea C, eds. From social vulnerability to resilience: measuring progress toward disaster risk reduction. United Nations University Institute for Environment and Human Security, Bonn, Germany, pp 108-120.

Bowen HL, 2013. Impact of a mass media campaign on bed net use in Cameroon. Malaria J 12:36.

Brooks N, Adger WN, Kelly PM, 2005. The determinants of vulnerability and adaptive capacity at the national level and the implications for adaptation. Global Environ Chang 15:151-63.

Chanda P, Hamainza B, Moonga HB, Chalwe V, Pagnoni F, 2011. Community case management of malaria using ACT and RDT in two districts in Zambia: achieving high adherence to test results using community health workers. Malaria J 10:158.

Checkley AM, Smith A, Smith V, Blaze M, Bradley D, Chiodini P, Whitty CJM, 2012. Risk factors for mortality from imported falciparum Malaria in the United Kingdom over 20 years: an observational study. Brit Med J 344:e2116.

Clay DC, 1992. Fighting an uphill battle: demographic pressure, the structure of landholding, and land degradation in Rwanda. US Agency for International Development and the Rwanda Ministry of Agriculture and Livestock, Washington, DC, USA and Kigali, Rwanda.

Clay DC, Johnson NE, 1992. Size of farm or size of family: which comes first? Pop Stud-J Demog 43:491-505.

Cromley EK, McLafferty SL, 2012. GIS and public health. The Guilford Press, New York, NY, USA.

Cutter SL, Boruff BJ, Shirley WL, 2003. Social vulnerability to environmental hazards. Soc Sci Quart 84:242-61.

Cutter SL, Mitchell JT, Scott MS, 2000. Revealing the vulnerability of people and places: a case study of Georgetown County, South Carolina. Ann Assoc Am Geogrs 90:713-37.

De Plaen R, Seka ML, Koutoua A, 2004. The paddy, the vector and the caregiver: lessons from an ecosystem approach to irrigation and malaria in Northern Côte d'Ivoire. Acta Trop 89:135-46.

de Smith MJ, Goodchild MF, Longley PA, 2015. Geospatial analysis: a comprehensive guide to principles, techniques and software tools. The Winchelsea Press, Winchelsea, UK.

Dickin SK, Schuster-Wallace CJ, Elliott SJ, 2013. Developing a vulnerability mapping methodology: applying the water-associated disease index to dengue in Malaysia. PLoS One 8:e63584.

Drãgut L, Csillik 0, Eisank C, Tiede D, 2014. Automated parameterisation for multi-scale image segmentation on multiple layers. ISPRS J Photogramm 88:119-27.

Dunn CE, Le Mare A, Makungu C, 2011. Malaria risk behaviours, sociocultural practices and rural livelihoods in southern Tanzania: implications for bednet usage. Soc Sci Med 72:408-17.

Fedderke JW, Perkins P, Luiz JM, 2006. Infrastructural investment in long-run economic growth: South Africa 1875-2001. World Dev 34:1037-59.

Fekete A, 2009. Validation of a social vulnerability index in context to river-floods in Germany. Nat Hazard Earth Syst 9:393-403.

Field AP, 2005. Discovering statistics using SPSS for Windows. SAGE Publication, London, UK.

Frazier TG, Thompson CM, Dezzani RJ, 2014. A framework for the development of the SERV model: a spatially explicit resilience-vulnerability model. Appl Geogr 51:158-72.

Gascon J, Merlos A, Madrenys N, Torres JM, Bada JL, 1988. Epidemiology of malaria in Nyarutovu (Rwanda): a clinical, parasitological and serological study. T Roy Soc Trop Med H 82:421-2.

Gething PW, Patil AP, Smith DL, Guerra CA, Elyazar IRF, Johnstone GL, 
Tatem AJ, Hay SI, 2011. A new world malaria map: Plasmodium falciparum endemicity in 2010. Malaria J 10:378.

González R, Ataíde R, Naniche D, Menéndez C, Mayor A, 2012. HIV and malaria interactions. Where do we stand? Expert Rev Anti-Infe 10:153-65.

Government of Rwanda, 2010. Mutual health insurance policy in Rwanda. Minstry of Health, Kigali, Rwanda.

Graves PM, Richards F0, Ngondi J, Emerson PM, Shargie EB, Endeshaw T, Ceccato P, Ejigsemahu Y, Mosher AW, Hailemariam A, Zerihun M, Teferi T, Ayele B, Mesele A, Yohannes G, Tilahun A, Gebre T, 2009. Individual, household and environmental risk factors for malaria infection in Amhara, Oromia and SNNP regions of Ethiopia. T Roy Soc Trop Med H 103:1211-20.

Hagenlocher M, 2013. Identifying and evaluating hotspots of climate change in Sahel and Western Africa. In: Cutter S, Corendea C, eds. From social vulnerability to resilience: measuring progress toward disaster risk reduction. United Nations University Institute for Environment and Human Security, Born, Germany, pp 93-107.

Hagenlocher M, Castro MC, 2015. Mapping malaria risk and vulnerability in the United Republic of Tanzania: a spatial explicit model. Popul Health Metr 13:2.

Hagenlocher M, Delmelle E, Casas I, Kienberger S, 2013. Assessing socioeconomic vulnerability to dengue fever in Cali, Colombia: statistical $v s$ expert-based modeling. Int J Health Geogr 12:36.

Hagenlocher M, Kienberger S, Lang S, Blaschke T, 2014. Implications of spatial scales and reporting units for the spatial modelling of vulnerability to vector-borne diseases. In: Jekel T, Car A, Strobl J, Griesebner G, eds. GI_Forum 2014: geospatial innovation for society. Wichmann, Heidelberg, Germany, pp 197-206.

Hakizimana E, Cyubahiro B, Rukundo A, Kabayiza A, Mutabazi A, Beach R, Patel R, Tongren JE, Karema C, 2014. Monitoring long-lasting insecticidal net (LLIN) durability to validate net serviceable life assumptions, in Rwanda. Malaria J 13:344.

Hakizimana E, Kazungu B, Patel R, Beach R, Williams J, Karema C, 2010. Entomological monitoring and evaluation for operational malaria control in Rwanda. Available from: Emmanuel_ASTMH_poster_Roopal291010.pdf

Hammerich A, Campbell OMR, Chandramohan D, 2002. Unstable malaria transmission and maternal mortality - experiences from Rwanda. Trop Med Int Health 7:573-6.

Hay SI, Cox J, Rogers DJ, Randolph SE, Sternk DI, Shanks GD, Myers MF, Snow RW, 2002. Climate change and the resurgence of malaria in the East African highlands. Nature 415:905-9.

Henninger SM, 2013a. Does the global warming modify the local Rwandan climate? Nat Sci 4:124-9.

Henninger SM, 2013b. Local climate changes and the spread of malaria in Rwanda. Health 5:728-34.

Hongoh V, Gatewood Hoen A, Aenishaenslin C, Waaub JP, Belanger D, Michel P, 2011. Spatially explicit multi-criteria decision analysis for managing vector-borne diseases. Int J Health Geogr 10:70.

Hudrliková L, 2013. Composite indicators as useful tool for international comparison: the Europe 2010 example. Prague Econ Pap 4:459-73.

Ijumba JN, Lindsay SW, 2001. Impact of irrigation on malaria in Africa: paddies paradox. Med Vet Entomol 15:1-11.

Ingabire CM, Alaii J, Hakizimana E, Kateera F, Muhimuzi D, Nieuwold I, Bezooijen K, Rulisa S, Kaligirwa N, Muvunyi C, Koenraadt CJM, Mutesa L, Van Vugt M, Van Den Borne B, 2014. Community mobilization for malaria elimination: application of an open space methodology in Ruhuha sector, Rwanda. Malaria J 13:167.

Ingabire CM, Rulisa A, Van Kempen L, Muvunyi C, Koenraadt CJ, Van Vugt M, Mutesa L, Van Den Borne B, Alaii J, 2015. Factors impeding the acceptability and use of malaria preventive measures: implications for malaria elimination in eastern Rwanda. Malaria J 14:136.

Ivan E, Crowther NJ, Mutimura E, Osuwat LO, Janssen S, Grobusch MP, 2013. Helminthic infections rates and malaria in HIV-infected pregnant women on anti-retroviral therapy in Rwanda. PLoS Neglect Trop D 7:e2380.

Ivan E, Crowther NJ, Rucogoza AT, Osuwat LO, Munyazesa E, Mutimura E, Njunwa KJ, Kakoma JB, Grobusch MP, 2012. Malaria and helminthic co-infection among HIV-positive pregnant women: prevalence and effects of antiretroviral therapy. Acta Trop 124:179-84.

Janssen W, 2005. Insecticide-treated nets: efficacy, impact and operational constraints. Hum Exchange 31:11-3.

Karema C, Aregawi MW, Rukundo A, Kabayiza A, Mulindahabi M, Fall IS, Gausi K, Williams R0, Lynch M, Cibulskis R, Ngabo F, Nyemazi JP, Ngamije D, Umulisa I, Newman R, Binagwaho A, 2012. Trends in malaria cases, hospital admissions and deaths following scaleup of anti-malarial interventions, 2000-2010, Rwanda. Malaria J 11:236.

Kateera F, Mens PF, Hakizimana E, Ingabire CM, Muragijemariya L, Karinda P, Grobusch MP, Mutesa L, van Vugt M, 2015. Malaria parasite carriage and risk determinants in a rural population: a malariometric survey in Rwanda. Malaria J 14:16.

Kibret S, Wilson GG, Tekie H, Petros B, 2014. Increased malaria transmission around irrigation schemes in Ethiopia and the potential of canal water management for malaria vector control. Malaria $\mathrm{J}$ $13: 360$.

Kienberger S, Blaschke T, Zaidi RZ, 2013a. A framework for spatio-temporal scales and concepts from different disciplines: the "vulnerability cube'. Nat Hazards 68:1343-69.

Kienberger S, Hagenlocher M, 2014. Spatial-explicit modeling of social vulnerability to malaria in East Africa. Int J Health Geogr 13:29.

Kienberger S, Hagenlocher M, Delmelle E, Casas I, 2013b. A WebGIS tool for visualizing and exploring socioeconomic vulnerability to dengue fever in Cali, Colombia. Geospat Health 8:313-6.

Kienberger S, Lang S, Zeil P, 2009. Spatial vulnerability units - expertbased spatial modelling of socio-economic vulnerability in the Salzach catchment, Austria. Nat Hazard Earth Syst 9:767-78.

Kilama M, Smith DL, Hutchinson R, Kigozi R, Yeka A, Lavoy G, Kamya MR, Staedke SG, Donnelly MJ, Drakeley C, 2014. Estimating the annual entomological inoculation rate for Plasmodium falciparum transmitted by Anopheles gambiae sl using three sampling methods in three sites in Uganda. Malaria J 13:111.

King RAR, Blackmore KL, 2013. Physical and political boundaries as barriers to the continuity of social vulnerability. Appl Geogr 44:79-87.

Kiszewski AE, Teklehaimanot A, 2004. A review of the clinical and epidemiologic burdens of epidemic malaria. Am Soc Trop Med $\mathrm{H}$ 71:128-35.

Ladner J, Leroy V, Simonon A, Karita E, Bogaerts J, De Clercq A, Van de Perre P, Dabis F, 2002. HIV infection, malaria, and pregnancy: a prospective cohort study in Kigali, Rwanda. Am Soc Trop Med H 66:56-60.

Lang S, Kienberger S, Tiede D, Hagenlocher M, Pernkopf L, 2014. Geons - domain-specific regionalization of space. Cartogr Geogr Inform 41:214-26.

Lang S, Zeil P, Kienberger S, Tiede D, 2008. Geons - policy-relevant geo-objects for monitoring high-level indicators. In: Car A, Griesebner G, Strobl J, eds. Geospatial crossroads@GI-Forum 2008, Proceedings of Geoinformatics Form. Wichmann, Heidelberg, Germany, pp 180-5.

Larmarange J, Vallo R, Yaro S, Msellati P, Meda N, 2011. Methods for mapping regional trends of HIV prevalence from Demographic and 
Health Surveys (DHS). Cybergeo 2011:558.

Lindsay SW, Martens WJM, 1998. Malaria in the African highlands: past, present and future. B World Health Organ 76:33-45.

Lizzi KM, Qualls WA, Brown SC, Beier JC, 2014. Expanding integrated vector management to promote healthy environments. Trends Parasitol 30:394-400.

Lu C, Chin B, Lewandowski JL, Basinga P, Hirschhorn LR, Hill K, Murray M, Binagwaho A, 2012. Towards universal health coverage: an evaluation of Rwanda mutuelles in its first eight years. PLoS One $7: \mathrm{e} 39282$

Lung T, Lavalle C, Hiederer R, Dosio A, Bouwer LM, 2013. A multi-hazard regional level impact assessment for Europe combining indicators of climatic and non-climatic change. Global Environ Chang 23:522-36.

Lwetoijera DW, Kiware SS, Mageni ZD, Dongus S, Harris C, Devine GJ, Majambere S, 2013. A need for better housing to further reduce indoor malaria transmission in areas with high bed net coverage. Parasite Vector 6:57.

Martens P, Kovats RS, Nijhof S, de Vries P, Livermore MTJ, Bradley DJ, Cox J, McMichael AJ, 1999. Climate change and future populations at risk of malaria. Global Environ Chang 9:89-107.

Mboera LEG, Mukabana WR, Njunwa KJ, Kabbale FG, 2014. Integrated research partnerships for malaria control through an ecohealth approach in East Africa: Kenya, Rwanda, Tanzania and Uganda projects. Final report. Available from: idl-bnc.idrc.ca/dspace/bitstream/10625/52443/1/IDL-52443.pdf

Meade MS, Earickson RJ, 2005. Medical geography. 2nd ed. Guilford Press, New York, NY, USA.

Meyrowitsch DW, Pedersen EM, Alifrangis M, Scheike T, Malecela MN, Magesa SM, Derua YA, Rwegoshora RT, Michael E, Simonsen PE, 2011. Is the current decline in malaria burden in sub-Saharan Africa due to a decrease in vector population? Malaria J 10:188.

Meyus H, Lips M, Caubergh H, 1962. L'état actuel du problème de paludisme d'altitude au Ruanda-Urundi. Ann Soc Belge Med Trop 42:771-82.

Morgan L, 2001. Community participation in health: perpetual allures, persistent challenge. Health Policy Plann 16:221-30.

Mwangangi JM, Midega J, Kahindi S, Njoroge L, Nzovu J, Githure J, Mbogo CM, Beier JC, 2012. Mosquito species abundance and diversity in Malindi, Kenya and their potential implication in pathogen transmission. Parasitol Res 110:61-71.

Nabahungu NL, Visser SM, 2013. Farmers' knowledge and perception of agricultural wetland management in Rwanda. Land Degrad Dev 24:363-74.

Nardo M, Saisana M, Saltelli A, Tarantola S, 2005. Tools for composite indicators building. Institute for the Protection and Security of the Citizen Econometrics and Statistical Support to Antifraud Unit, Ispra, Italy.

Nishimwe C, Kerr J, 2012. The effectiveness of malaria health education provided to pregnant women by nurses at a selected health centre in Rwanda. Afr J Nurs Midwifery 14:63-76.

NISR, 2012a. Fourth population and housing census 2012. Thematic report: migration and spatial mobility. National Institute of Statistics of Rwanda, Kigali City, Rwanda.

NISR, 2012b. Fourth population and housing census. Thematic report: characteristics of households and housing. National Institute of Statistics of Rwanda, Kigali City, Rwanda.

NISR, 2012c. Rwanda demographic and health survey 2010. National Institute of Statistics of Rwanda, Kigali City, Rwanda.

Nyandekwe M, Nzayirambaho M, Kakoma JB, 2014. Universal health coverage in Rwanda: dream or reality. Pan Afr Med J 17:232.
OECD, 2008. Handbook on constructing composite indicators: methodology and user guide. Organization for Economic Co-operation and Development, Paris, France.

Okwaraji YB, Cousens S, Berhane Y, Mulholland K, Edmond K, 2012. Effect of geographical access to health facilities on child mortality in rural Ethiopia: a community based cross sectional study. PLoS One 7:e33564.

0’Meara WP, Noor A, Gatakaa H, Tsofa B, McKenzie FE, Marsh K, 2009. The impact of primary health care on malaria morbidity - defining access by disease burden. Trop Med Int Health 14:29-35.

Onwujekwe 0, Hanson K, Uzochukwu B, 2011. Do poor people use poor quality providers? Evidence from the treatment of presumptive malaria in Nigeria. Trop Med Int Health 16:1087-98.

Packard RM, 2007. The making of a tropical disease: a short history of malaria. John Hopkins University Press, Baltimore, MD, USA.

Pattanaaik SK, Singh OP, Sahoo RN, Singh DK, 2008. Irrigation induced soil salinity mapping through principal component analysis of remote sensing data. J Agr Physics 8:29-36.

Perschon-Heyen J, 2001. Non-motorised transport and its socio-economic impact on poor households in Africa: cost-benefit analysis of bicycle ownership in rural Uganda. The Institute for Transportation and Development Policy, Hamburg, Germany.

Ricci F, 2012. Social implications of malaria and their relationships with poverty. Mediterr J Hematol Infect Dis 4:e2012048.

Richmond AK, Malcomb D, Ringler K, 2015. Household vulnerability mapping in Africa's Rift Valley. Appl Geogr 63:380-95.

Roll Back Malaria, 2005. Global strategic plan 2005-2015. Roll Back Malaria partnership. World Health Organization, Geneva, Switzerland.

Rytkönen MJP, 2004. Not all maps are equal: GIS and spatial analysis in epidemiology. Int Journal Circumpol Heal 63:9-24.

Slottje DJ, 1991. Measuring the quality of life across countries. Rev Econ Stat 73:684-93.

Snow RW, Craig MH, Deichmann U, le Sueur D, 1999a. A preliminary continental risk map for malaria mortality among African children. Parasitol Today 15:99-104.

Snow RW, Craig M, Deichmann U, Marsh K, 1999b. Estimating mortality, morbidity and disability due to malaria among Africa's nonpregnant population. B World Health Organ 77:624-40.

Snow RW, Omumbo JA, Lowe B, Molyneux CS, Obiero JO, Palmer A, Weber MW, Pinder M, Nahlen B, Obonyo C, Newbold C, Gupta S, Marsh K, 1997. Relation between severe malaria morbidity in children and level of Plasmodium falciparum transmission in Africa. Lancet 349:1650-4.

Stern DI, Gething PW, Kabaria CW, Temperley WH, Noor AM, Okiro EA, Shanks GD, Snow RW, Hay SI, 2011. Temperature and malaria trends in highland East Africa. PLoS One 6:e24524.

Stich A, Zwicker M, Steffen T, Köhler B, Fleischer K, 2003. Old age as risk factor for complications of malaria in non-immune travelers. Deut Med Wochenschr 128:309-14.

Thaxton M, 2009. Integrating population, health, and environment in Rwanda. Available from: www.prb.org/pdf09/phe-rwanda.pdf

Turuse EA, Gelaye KA, Beyen TK, 2014. Determinants of delay in malaria prompt diagnosis and timely treatment among under-five children in Shashogo Woreda, Hadiya Zone, Southern Ethiopia: a case control study. Health 6:950-9.

UNECA, 2009. Sixth session of the Committee on Food Security and Sustainable Development (CFSSD-6). Available from: http://wwwl. uneca.org/cfssd6/home_cfssd.aspx

USAID, 2013. President's malaria initiative. Malaria operational plan, Rwanda FY 2013. United States Agency International Development, 
Washington, DC, USA.

USAID, 2014. President's malaria initiative. Malaria operational plan, Rwanda FY 2014. United States Agency International Development, Washington DC, USA.

US Census Bureau, 2011. Rwanda 5-year age/sex group population estimates 2000-2015: third order administrative divisions. US Census Bureau, Washington, DC, USA.

Van Geertruyden JP, Ntakirutimana D, Erhart A, Rwagacondo C, Kabano A, D'Alessandro U, 2005. Malaria infection among pregnant women attending antenatal clinics in six Rwandan districts. Trop Med Int Health 10:681-8.

Verhoeff FH, Brabin BJ, Hart A, Chimsuku L, Kazembe P, Broadhead RL, 1999. Increased prevalence of malaria in HIV-infected pregnant women and its implications for malaria control. Trop Med Int Health 4:5-12.

Vyas S, Kumaranayake L, 2006. Constructing socio-economic status indices: how to use principal components analysis. Health Policy Plann 21:459-68.

Wandiga S0, Opondo M, Olago D, Githeko A, Githui F, Marshall M, Downs T, Opere A, Ouma CGO, Yanda PZ, Kangalawe R, Kabumbuli R, Kathuri J, Apindi E, Olaka L, Ogallo L, Mugambi P, Sigalla R, Nanyunja R, Baguma T, Achola P, 2010. Vulnerability to epidemic malaria in the highlands of Lake Victoria basin: the role of climate change/variability, hydrology and socio-economic factors. Climatic Change 99:473-97.

WHO, 2000. The African Summit on Roll Back Malaria. Summary report. Geneva, World Health Organization, Geneva, Switzerland. Available from: http://archiverbm.rollbackmalaria.org/docs/abuja_ sumrep.htm

WHO, 2006. Integrating poverty and gender into health programmes: a sourcebook for health professionals (module on malaria). World Health Organization, Geneva, Switzerland.

WHO, 2011. World malaria report. Global malaria programme. World Health Organization, Geneva, Switzerland.

WHO, 2013. World malaria report. Global malaria programme. World Health Organization, Geneva, Switzerland.

WHO, 2014. Issue brief series: vector-borne diseases. Healthy environments for children alliance. World Health Organization, Geneva, Switzerland. Available from: http://www.who.int/heca/infomaterials/en/vector-borne.pdf

WorldPop, 2010. Available from: http://www.worldpop.org.uk/data/summary/?contselect=Africa\&countselect=Rwanda\&typeselect=Popul ation

Zeekaf A, 2014. A thousand hills of health insurance: including the poorest groups in Rwanda through community based health insurance. Master Thesis. Utrecht University, Utrecht, The Netherlands. 